\title{
Relative host plant species use by the lantana biological control agent Aconophora compressa (Membracidae) across its native and introduced ranges
}

\author{
Andrew G. Manners ${ }^{\mathrm{a}, \mathrm{b}, \mathrm{c}, *}$, William A. Palmer ${ }^{\mathrm{a}, \mathrm{c}}$, Armando Burgos ${ }^{\mathrm{d}}$, Jayd McCarthy ${ }^{\mathrm{c}}$, Gimme H. Walter ${ }^{\mathrm{a}, \mathrm{b}}$ \\ ${ }^{a}$ CRC for Australian Weed Management, The University of Adelaide, South Australia, Australia \\ ${ }^{\mathrm{b}}$ School of Biological Sciences, The University of Queensland, Brisbane, Australia \\ ${ }^{\mathrm{c}}$ Queensland Department of Employment, Economic Development and Innovation, Australia \\ ${ }^{\mathrm{d}}$ Centro de Investigaciones Biológicas, Universidad Autonoma del Estado de Morelos, Mexico
}

\section{A R T I C L E I N F O}

\section{Article history:}

Received 14 October 2010

Accepted 24 May 2011

Available online 31 May 2011

\section{Keywords:}

Aconophora compressa

Citharexylum spinosum

Duranta erecta

Fiddlewood

Lantana camara

Multiple host plant use

Non-target effects

Polyphagy

Primary host plant

Secondary host plant

Weed biological control

\begin{abstract}
A B S T R A C T
Aconophora compressa Walker (Hemiptera: Membracidae) was released in 1995 against the weed lantana in Australia, and is now found on multiple host plant species. The intensity and regularity at which $A$. compressa uses different host species was quantified in its introduced Australian range and also its native Mexican range. In Australia, host plants fell into three statistically defined categories, as indicated by the relative rates and intensities at which they were used in the field. Fiddlewood (Citharexylum spinosum L.: Verbenaceae) was used much more regularly and at higher densities than any other host sampled, and alone made up the first group. The second group, lantana (Lantana camara L.: Verbenaceae; pink variety) and geisha girl (Duranta erecta L.: Verbenaceae), were used less regularly and at much lower densities than fiddlewood. The third group, Sheena's gold (another variety of $D$. erecta), jacaranda (Jacaranda mimosifolia D. Don: Bignoniaceae) and myoporum (Myoporum acuminatum $\mathrm{R}$. Br.: Myoporaceae), were used infrequently and at even lower densities. In Mexico, the insect was found at relatively low densities on all hosts relative to those in Australia. Densities were highest on L. urticifolia, D. erecta and Tecoma stans (L.) Juss. ex Kunth (Bignoniaceae), which were used at similar rates to one another. It was found also on a few other verbenaceous and non-verbenaceous host species but at even lower densities. The relative rate at which Citharexylum spp. and $L$. urticifolia were used could not be assessed in Mexico because $A$. compressa was found on only one plant of each species in areas where these host species co-occurred. The low rate at which A. compressa occurred on fiddlewood in Mexico is likely to be an artefact of the short-term nature of the surveys or differences in the suites of Citharexylum and Lantana species available there. These results provide further incentive to insist on structured and quantified surveys of non-target host use in the native range of potential biological control agents prior to host testing studies in quarantine.
\end{abstract}

Crown Copyright @ 2011 Published by Elsevier Inc. All rights reserved.

\section{Introduction}

Field surveys of herbivorous species on their host plants are essential for identifying candidates for weed biological control agents (Goolsby et al., 2006; Sheppard et al., 2006a). When hosttesting results suggest the biocontrol agent is host specific, its release, once approved, is usually made on the assumption it will attack only the target weed. Unanticipated non-target effects have the potential to be devastating to the environment, damage the reputation of biological control (Simberloff and Stiling, 1996; Louda et al., 2003) and jeopardise permission for future releases of other agents (Sheppard et al., 2006b). Past mistakes of this nature

\footnotetext{
* Corresponding author. Present address: Department of Employment, Economic Development and Innovation, Agriscience Queensland, Redlands Research Station, P.O. Box 327, Cleveland 4163, Australia. Fax: +61 732863094.

E-mail address: andrew.manners@deedi.qld.gov.au (A.G. Manners).
}

do, however, provide a basis for understanding how and why such errors were made and should provide insights to improve the process by which biocontrol agents are selected and sanctioned for release (Briese, 2005).

Host specificity testing of candidate biocontrol agents relies mostly on data collected from glasshouse and laboratory studies in which a range of potential hosts are exposed to the herbivore species of interest. Plant species that are economically and ecologically important, and which are deemed to be at potential risk, must be included. So, too, must plant species, or close relatives, with which that agent has been associated in its native range. All other available information on the herbivore species, in relation to its association with the target weed (and other host species), is normally gathered prior to host testing, and this includes data from insect collections, published literature and surveys and personal knowledge of field collectors. This approach to host testing has several recognised shortcomings, including the inadvertent 

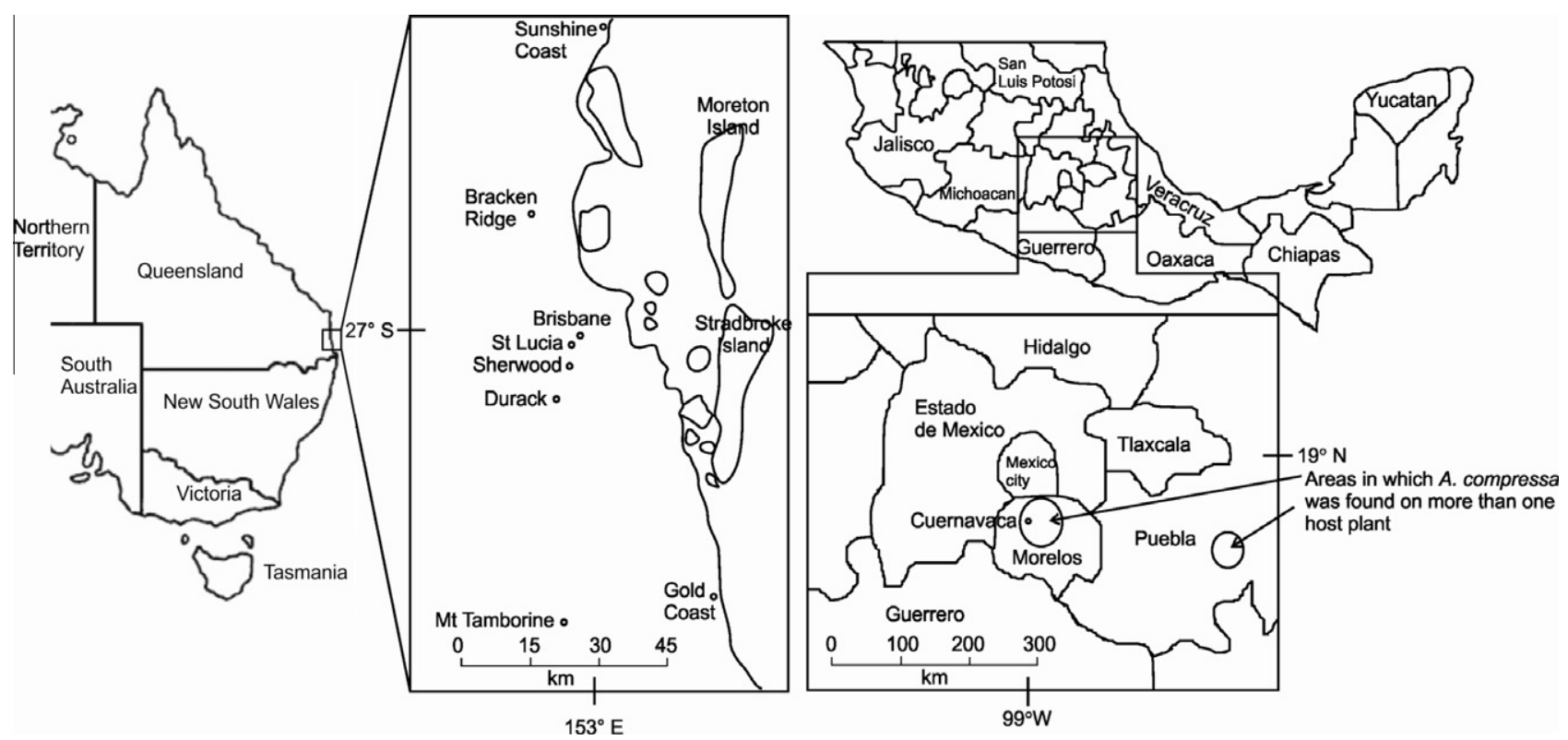

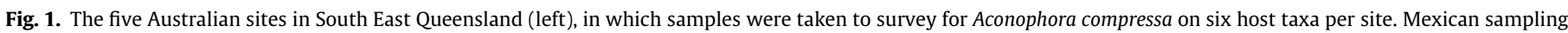
areas (right) in which $A$. compressa was found on more than one host plant species are indicated with arrowed circles.

exclusion from tests of relevant host plant taxa through a lack of knowledge (Wapshere, 1974) and the unintended obviation, in relatively confined glasshouse conditions, of the long distance cues that are usually used by the insects to locate their hosts in the field (Wapshere et al., 1989; Marohasy, 1996; Withers and Barton Browne, 1998).

The limitations of formal laboratory host testing suggest that field studies in the native range of the target weed will always be important for determining the array of host species used by candidate biocontrol agents, even though some of the significant plant species in the area targeted for release of the potential agents may not be present in the native range. Quantification of the relative intensity and regularity of host species use by the herbivore across all potential host species in its native range are crucial to determining the relationship that the herbivore shares with each of the host plant species. Primary hosts are those that have the herbivore species of interest present on them most regularly and in relatively high numbers, and such hosts are predicted to have the entire range of features (stimuli) by which these herbivores detect, localise and use host plants (Walter and Benfield, 1994; Rajapakse et al., 2006). Secondary and incidental host plant species are predicted to have only a subset of these features and so are used less regularly in the field and in relatively lower numbers (Walter and Benfield, 1994; Milne and Walter, 2000; Walter, 2003, Chapter 7; Rajapakse et al., 2006).

The host relationships outlined above are currently defined in relation to quantitative data on the use of host species in the field. The relative intensity of the interaction across host species is, in turn, influenced primarily by the sensory physiology and behaviour of the herbivore species in question. In theory, therefore, it should be possible to develop an approach to predicting the host relationships of a species upon its introduction into a new area, at least in relation to all the hosts included in the native range study. However, it should be possible to use information on the relationships in the native range to 'calibrate' for those plants that do not exist in the native range (Briese, 2005). Identification of the primary, secondary and incidental host relationships are shown, in the results presented below, to provide a powerful adjunct to host specificity testing. The influence of ecological factors extraneous to the insect plant interaction, such as predation, could influence how a plant may be categorised and may have to be accommodated.
Aconophora compressa was introduced into Australia from Mexico in 1995 for the biological control of lantana (Lantana camara L.: Verbenaceae) (Palmer et al., 1996) but in Australia is mostly associated with fiddlewood (Citharexylum spinosum L.: Verbenaceae) (Dhileepan et al., 2006; Manners and Walter, 2009; Manners et al., 2010), a tree native to the Caribbean. The available data for A. compressa from field and laboratory studies indicate that fiddlewood is a primary host, whereas lantana and the varieties of $D$. erecta, (i.e. geisha girl and Sheena's gold) are secondary hosts (Dhileepan et al., 2006; Manners and Walter, 2009; Manners et al., 2010).

A. compressa is ideal for investigating aspects of the herbivorehost interaction that are relevant to the pre-release evaluation of biocontrol agents because it uses multiple hosts, much of its basic biology on a number of hosts is known (Manners and Walter, 2009; Manners et al., 2010), and it has already been introduced into a new area where it interacts with hosts differently from the way originally anticipated. Furthermore, a number of plant species exist in both Mexico and Australia for which the insect plant interaction has been studied in Australia, including $D$. erecta (variety not known in Mexico), jacaranda (Jacaranda mimosifolia), lantana ( $L$. camara in Australia is thought to be most closely related to L. urticifolia from Mexico (Scott 2002), although recent evidence suggests that it may be more closely related to lantana from Venezuela and the Dominican Republic (R. Watts, CSIRO, Plant Industries, Canberra, personal communication). In addition, many species of Citharexylum exist in Mexico, although $C$. spinosum has not been recorded there (Moldenke, 1942). Meaningful comparisons of the host plant relationships of $A$. compressa can thus be made across the native and introduced ranges.

In particular, the following questions were addressed through quantified field sampling in Australia and Mexico. Does field host use in the native range correlate to that in the introduced range of $A$. compressa? Could the quantified host use of $A$. compressa in Mexico across all host plants have thus been used to predict the observed behaviour of this species after its release in Australia and, if not, what are the possible explanations? Answers to these questions should improve our understanding of insect-host relationships in general and lead to recommendations for host testing methods that should reduce the risk associated with releasing an organism into a new environment. 

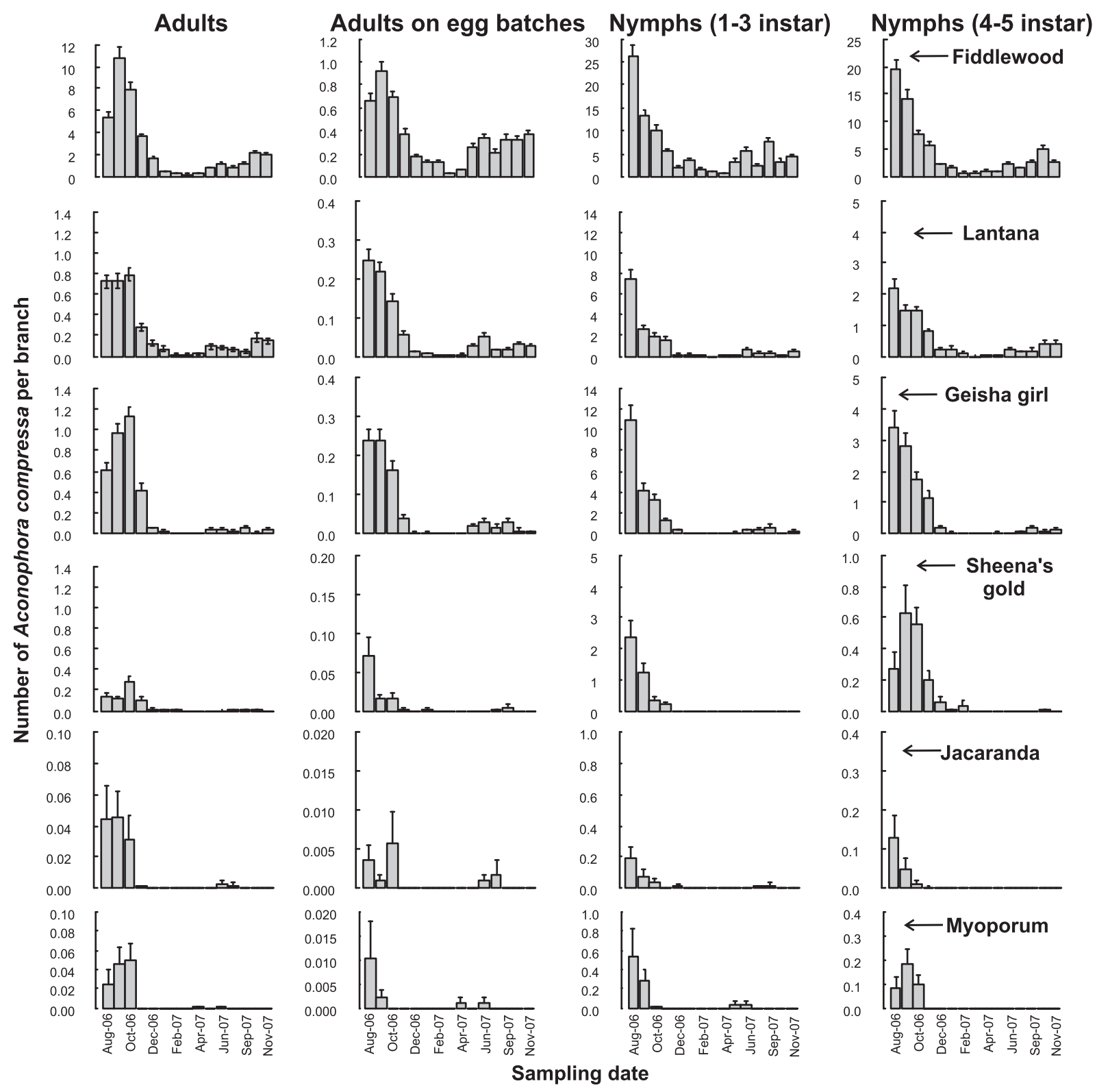

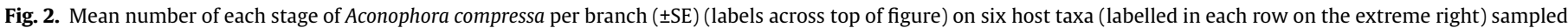

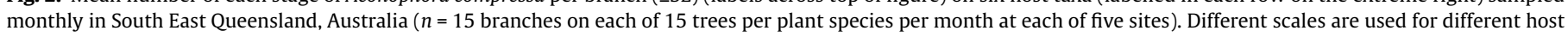
plants and stages of insect. Sample number ( $x$-axis) represents successive months between August 2006 and November 2007 , except October 2007.

\section{Methods}

\subsection{Surveys in Australia}

\subsubsection{General methods}

A survey was conducted to quantify the regularity and intensity at which A. compressa used different host species in South East Queensland (SEQ), Australia. Six plant taxa were monitored at each of five sites, Bracken Ridge $\left(27^{\circ} 19^{\prime} 33^{\prime \prime} \mathrm{S} 153^{\circ} 01^{\prime} 28^{\prime \prime} \mathrm{E}\right)$, St Lucia $\left(27^{\circ} 29^{\prime} 54^{\prime \prime} \mathrm{S} 153^{\circ} 00^{\prime} 04^{\prime} \mathrm{E}\right)$, Sherwood $\left(27^{\circ} 31^{\prime} 53^{\prime \prime} \mathrm{S} 152^{\circ} 58^{\prime} 53^{\prime \prime} \mathrm{E}\right)$, Durack $\left(27^{\circ} 35^{\prime} 19^{\prime \prime} \mathrm{S} 153^{\circ} 00^{\prime} 04^{\prime \prime}\right)$ and Mt Tamborine $\left(27^{\circ} 55^{\prime} 20^{\prime \prime} \mathrm{S}\right.$ $153^{\circ} 12^{\prime} 21^{\prime \prime} \mathrm{E}$ ) (Fig. 1). Four taxa were verbenaceous (fiddlewood, lantana - pink-edged red variety which is common in SEQ and two varieties of $D$. erecta, namely geisha girl and Sheena's gold) and two were non-verbenaceous (jacaranda and myoporum, Myoporum acuminatum). Each month at each site, the numbers of adults, females attending egg batches, early instar nymphs (first to third) and late instar nymphs (fourth and fifth) were counted
Table 1

Linear mixed effects ANOVA, with site modelled as a random factor, on the proportion of branches with Aconophora compressa in any developmental stage on different host plants. Different letters next to $p$-values indicate significant differences across host taxa.

\begin{tabular}{lllll}
\hline Treatment & $t$-Value & Df & $P$-value & $\begin{array}{l}\text { Total proportion } \\
\text { of branches }\end{array}$ \\
\hline Intercept (fiddlewood) & 15.82 & 226 & $<0.0001 \mathrm{a}$ & 0.236 \\
Lantana & -8.83 & 226 & $<0.0001 \mathrm{~b}$ & 0.050 \\
Geisha girl & -7.46 & 226 & $<0.0001 \mathrm{~b}$ & 0.040 \\
Sheena's gold & -10.89 & 226 & $<0.0001 \mathrm{c}$ & 0.009 \\
Myoporum & -10.11 & 226 & $<0.0001 \mathrm{c}$ & 0.002 \\
Jacaranda & -12.26 & 226 & $<0.0001 \mathrm{c}$ & 0.002 \\
Sine (time) & 3.46 & 226 & 0.0006 & NA \\
\hline
\end{tabular}

on 15 randomly selected branches on each of 15 trees of each taxon that had been marked with aluminium tags. Specific branches were not marked or re-sampled each month, although re-sampling may 

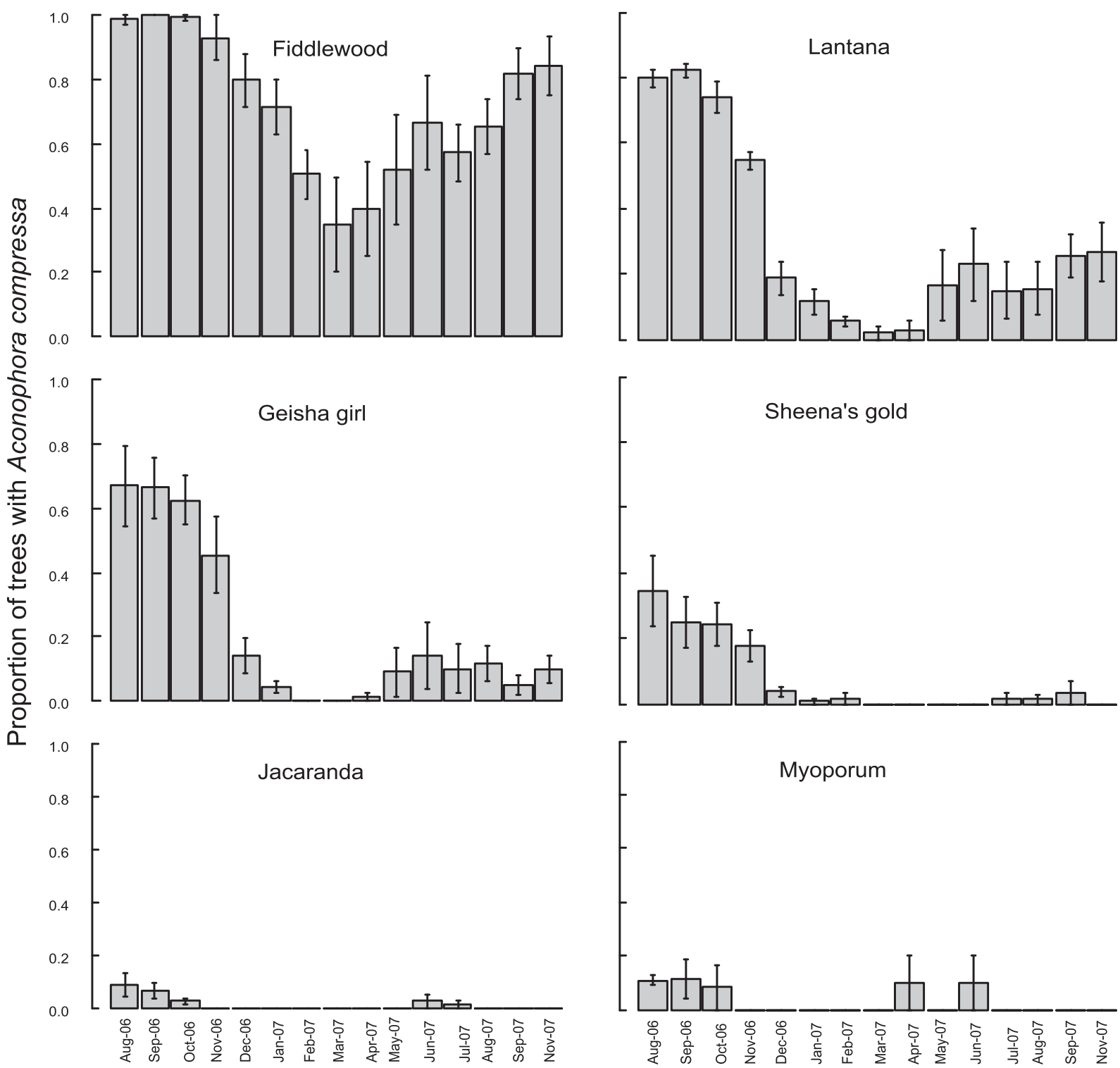

\section{Sampling date}

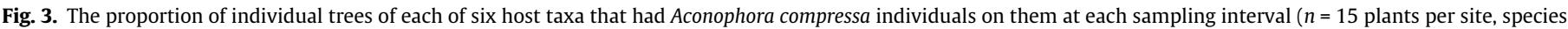
and month) in South East Queensland, Australia. Proportions were calculated for each site and used to calculate standard errors ( $n=5$ sites).

have occurred incidentally. All branches from all plant taxa sampled were less than $2.5 \mathrm{~m}$ from the ground.

Plants were sampled monthly in a repeated measures design between August 2006 and November 2007 (except Bracken Ridge, which was not sampled in August 2006, and no sites were sampled in October 2007). All plants at each site were within a $2 \mathrm{~km}$ radius of the site centre (Fig. 1) and were most often within a $1 \mathrm{~km}$ radius of co-ordinates stated above. All sites, except Mt Tamborine, were chosen because sufficient plants of each species were present. Mt Tamborine was chosen because of its relatively high altitude and cooler climate and these conditions may contribute to relatively high survival by $A$. compressa during high summer temperatures (Dhileepan et al., 2005). Only three plants of myoporum were found at Mt Tamborine, and then only in February 2007.

Most plants were in suburban gardens and subject to periodic pruning. Plants that were heavily pruned during the study were omitted until sufficient regrowth was available. A few plants that were removed by gardeners and, for sampling purposes, were re- placed with another nearby plant that was sampled monthly thereafter. Where individual plants could not be distinguished, e.g. in thickets of lantana and myoporum, a $1 \mathrm{~m}$ section of the entire growth was marked and monitored consistently. The leaf rachis of jacaranda was treated as a "branch" for the purposes of the survey and analysis because $A$. compressa uses these parts almost exclusively when on jacaranda.

All analyses were conducted in $\mathrm{R}$ version 2.6.2. Survey methods were designed with the intent of conducting repeated measures statistical analysis with random effects for site and individual plant. More than $90 \%$ of the data were, however, represented by zeroes and consequently broke the assumptions of all such analyses attempted (i.e. a variety of models using lme, glmmPQL, gamlss and gam in R), so the data were analysed as described in the following subsections.

Climatic data were collected for each site from the Australian Bureau of Meteorology (http://www.longpaddock.qld.gov.au/silo/ datadrill/index.frames.html). Temperatures above $30{ }^{\circ} \mathrm{C}$ cause sig- 


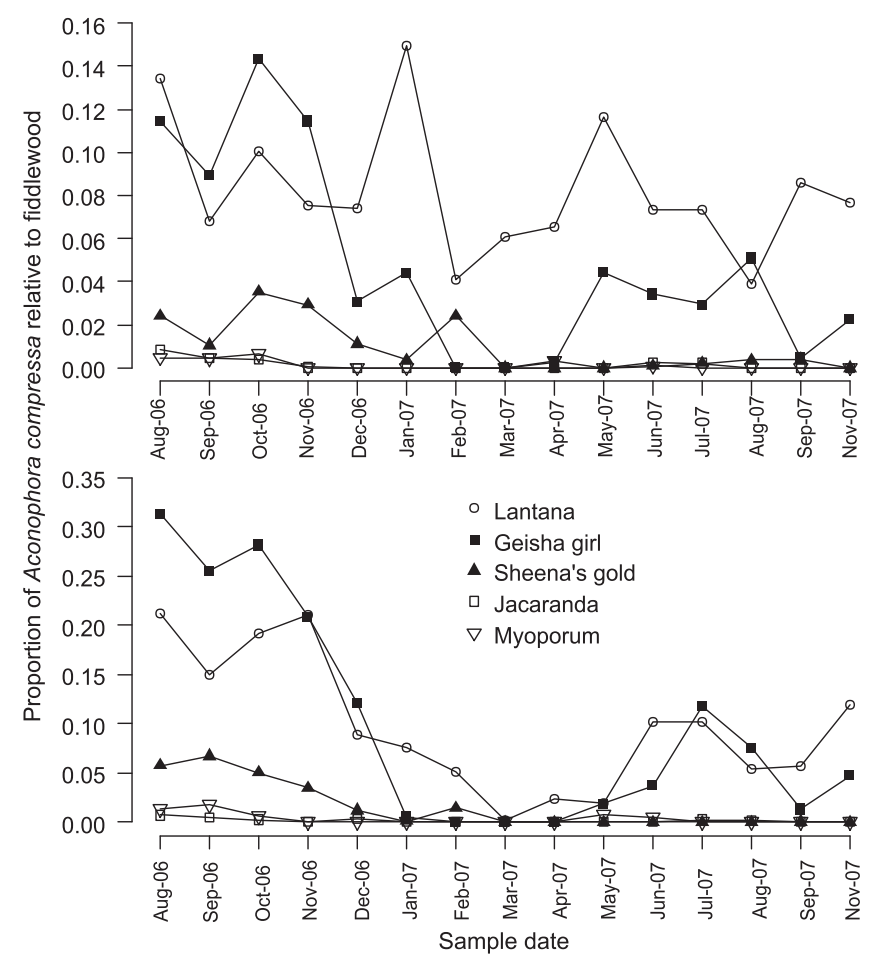

Fig. 4. The proportion of adult (top graph) and nymphal (bottom graph) Aconophora compressa on lantana, geisha girl, Sheena's gold, myoporum and jacaranda relative to the proportion on fiddlewood at the time of sampling. Fiddlewood is represented by values of one every month but this is not shown on the graphs.

nificant levels of mortality for A. compressa (Dhileepan et al., 2005). Therefore, for each month and site, the maximum temperature, the total number of days with $30^{\circ} \mathrm{C}$ or above, the longest period with consecutive days with $30^{\circ} \mathrm{C}$ or above and the mean rainfall were retrieved. Means and standard errors were calculated for each variable across sites.

\subsubsection{Intensity}

To examine differences in the intensity of host use across the plant taxa, the proportion of branches with $A$. compressa (any number and any developmental stage) was calculated for each month, site and taxon and arc-sine square root transformed. A linear mixed effects ANOVA was used to determine differences in host use across the plant taxa. The transformed proportion of branches with $A$. compressa was modelled by host taxon and the sine of time (to account for oscillating abundance of the insects over time) and site was modelled as a random factor. A power variance structure, representing a variance covariate given by the fitted values (the default setting of the varPower function), was also modelled. A generalised linear hypothesis test based on a Tukey test was used to determine significant differences across host taxa.

The mean number of each stage of $A$. compressa (unsexed adults, females on egg batches, early nymphs and late nymphs) per branch was plotted for each host plant per month to illustrate relative field host use across the plant taxa sampled. The pattern of infestation that was typical for individual plants was obscured when data were averaged across those individuals. Therefore the mean number of each life-stage of $A$. compressa was also plotted for each individual plant, of a selected subset of plants over time for fiddlewood, lantana and geisha girl to highlight typical temporal patterns of host use.

The proportion of plants with $A$. compressa was plotted for each plant taxon each month. In addition, the proportion of adult and nymphal $A$. compressa on each host plant taxon was plotted relative to fiddlewood for each month sampled.

\subsubsection{Regularity}

The presence of each stage of $A$. compressa on individual plants of each taxon was plotted to measure the regularity of host use over time and to calculate various summary statistics. Individual plants sampled for at least eight months (about half the entire sampling period) were included in the following analysis. The percentages of plants upon which $A$. compressa were present and absent in every month sampled were calculated separately. The percentage of months in which $A$. compressa was present on each plant and the longest continuous sequence of months through which $A$. compressa was present and absent were also calculated separately. These statistics were presented as a percentage of the total number of months sampled for each individual plant, to account for differences in the number of months sampled across individuals. Individual plants were scored positively every month that at least one $A$. compressa individual was present.

\subsection{Survey in Mexico}

A 3 week field survey was conducted in Mexico (within the native range of $A$. compressa) between January 23 and February 14, 2007. Plants were sampled as per the Australian surveys, but the number of plants sampled in any given area was not limited to 15 plants (as in Australian surveys) because repeated measures were not possible. The field survey was concentrated in the state of Morelos (Fig. 1) as this is considered an area of relatively high A. compressa abundance (Palmer et al., 1996). Plants were also searched in the following states: Mexico, Puebla, Tlaxcala and Guerrero (Fig. 1). Surveys were conducted along major and minor roadways and were more concentrated in areas with relatively high soil moisture, as indicated by lush, green foliage. Lantana urticifolia, Citharexylum spp. (probably two species that were 2$3 \mathrm{~m}$ shrubs, unlike C. spinosum in Australia which is a tall tree), jacaranda, T. stans and other verbenaceous plants were actively sought, although plants in moderate abundance in any given area were searched for $A$. compressa. The locations of plants of various Citharexylum spp. were sought with reference to herbarium specimens from the National Herbarium of Mexico, Mexico City. Insect specimens from all host species were identified by Chris Dietrich of the Illinois Natural History Survey. The data were split into two groups based on geographic location: Morelos and Puebla. Since there were no repeated measures and distinct sites were not identified (and which acted as replicates in the Australian analysis), formal statistical analysis was not conducted. Non-overlapping 95\% confidence intervals were therefore used to indicate differences in abundance across host taxa.

\section{Results}

\subsection{Surveys in Australia}

\subsubsection{Intensity and regularity}

Three distinct and significantly different groups of plant species could be circumscribed by the numbers of $A$. compressa they hosted in the field. Fiddlewood hosted significantly more insects per branch than any other host (Fig. 2), had consistently more branches with $A$. compressa (Table 1 ) and alone made up the first group. The second group consisted of lantana and geisha girl and the third Sheena's gold, myoporum and jacaranda (Fig. 2; Table 1). The proportion of individual plants of each taxon with A. compressa (Fig. 3), and the proportion of all $A$. compressa adults and nymphs collected 
Table 2

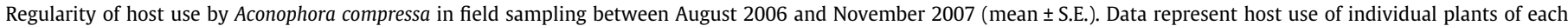
taxon that were surveyed for at least eight of the 15 months sampled ( $n$ for each host type is in brackets in the left hand column).

\begin{tabular}{|c|c|c|c|c|c|c|c|c|}
\hline \multirow[t]{2}{*}{ Treatment $(n)$} & \multirow{2}{*}{$\begin{array}{l}\text { Plants that had } \\
\text { A. compressa } \\
\text { for the entire } \\
\text { sampling period (\%) }\end{array}$} & \multirow{2}{*}{$\begin{array}{l}\text { Plants that had no } \\
\text { A. compressa } \\
\text { for entire sampling } \\
\text { period (\%) }\end{array}$} & \multicolumn{2}{|c|}{$\begin{array}{l}\text { Mean longest continuous time } \\
\text { period without } A \text {. compressa }\end{array}$} & \multicolumn{2}{|c|}{$\begin{array}{l}\text { Mean number of months that } \\
\text { plants had } A \text {. compressa }\end{array}$} & \multicolumn{2}{|c|}{$\begin{array}{l}\text { Mean longest continuous time } \\
\text { period with } A \text {. compressa }\end{array}$} \\
\hline & & & $\begin{array}{l}\text { \% Survey } \\
\text { period }\end{array}$ & $\begin{array}{l}\text { Monthly } \\
\text { equivalent }\end{array}$ & $\begin{array}{l}\% \text { survey } \\
\text { period }\end{array}$ & $\begin{array}{l}\text { Monthly } \\
\text { equivalent }\end{array}$ & $\begin{array}{l}\text { \% Survey } \\
\text { period }\end{array}$ & $\begin{array}{l}\text { Monthly } \\
\text { equivalent }\end{array}$ \\
\hline Fiddlewood (74) & 8.1 & 0.0 & $28.9 \pm 2.2$ & $4.3 \pm 0.3$ & $66.6 \pm 2.3$ & $10.0 \pm 0.3$ & $48.0 \pm 2.7$ & $7.2 \pm 0.4$ \\
\hline Lantana (85) & 0.0 & 12.9 & $62.2 \pm 2.6$ & $9.3 \pm 0.4$ & $26.0 \pm 1.9$ & $3.9 \pm 0.3$ & $17.7 \pm 1.3$ & $2.7 \pm 0.2$ \\
\hline Geisha girl (78) & 0.0 & 18.0 & $72.5 \pm 2.5$ & $10.9 \pm 0.4$ & $20.9 \pm 1.9$ & $3.1 \pm 0.3$ & $16.1 \pm 1.5$ & $2.4 \pm 0.2$ \\
\hline Sheena's gold (72) & 0.0 & 54.2 & $90.7 \pm 1.5$ & $13.6 \pm 0.2$ & $7.2 \pm 1.2$ & $1.1 \pm 0.2$ & $6.6 \pm 1.1$ & $1.0 \pm 0.2$ \\
\hline Myoporum (65) & 0.0 & 80.0 & $96.4 \pm 1.3$ & $14.5 \pm 0.2$ & $2.4 \pm 0.7$ & $0.4 \pm 0.1$ & $2.2 \pm 0.6$ & $0.3 \pm 0.1$ \\
\hline Jacaranda (73) & 0.0 & 82.2 & $97.3 \pm 1.0$ & $14.6 \pm 0.2$ & $1.8 \pm 0.5$ & $0.3 \pm 0.1$ & $1.6 \pm 0.5$ & $0.2 \pm 0.1$ \\
\hline
\end{tabular}

at each sampling time on each host species, relative to the proportion on fiddlewood plants (Fig. 4), followed this same trend.

On average, $A$. compressa was present continuously on fiddlewood, lantana and geisha girl (for all but 2 months on the last plant species) (Figs 2 and 4). When individual plants were inspected for continuity of $A$. compressa presence, however, it was only fiddlewood that hosted them persistently (Table 2 ), as indicated by the data from selected individual plants in Fig. 5. On lantana and geisha girl, by contrast, individual plants were never used continuously (Fig. 5; Table 2). The longest continuous stretch during which $A$. compressa was recorded on lantana and geisha girl was, on average, about 2-3 months (Table 2), much shorter than that observed on fiddlewood, about 7 months (Table 2). Fiddlewood was the only plant taxon for which $A$. compressa was found on every plant over the sample period (Table 2 ) and, on average, individual trees harboured $A$. compressa about 10 of the 15 months sampled, i.e. $66.6 \%$ (Table 2). This is in stark contrast to the next most frequently used host, lantana, in which individual trees harboured the insects on average for about four of the 15 months sampled, i.e. $26.0 \%$ (Table 2). A. compressa was not found on any plant, besides fiddlewood, for the entire sample period and was never found on about $13 \%$ of lantana plants sampled (Table 2). In summary, the data indicate that fiddlewood was used much more regularly (Table 2) and at much higher intensities (Figs 2-5) than any
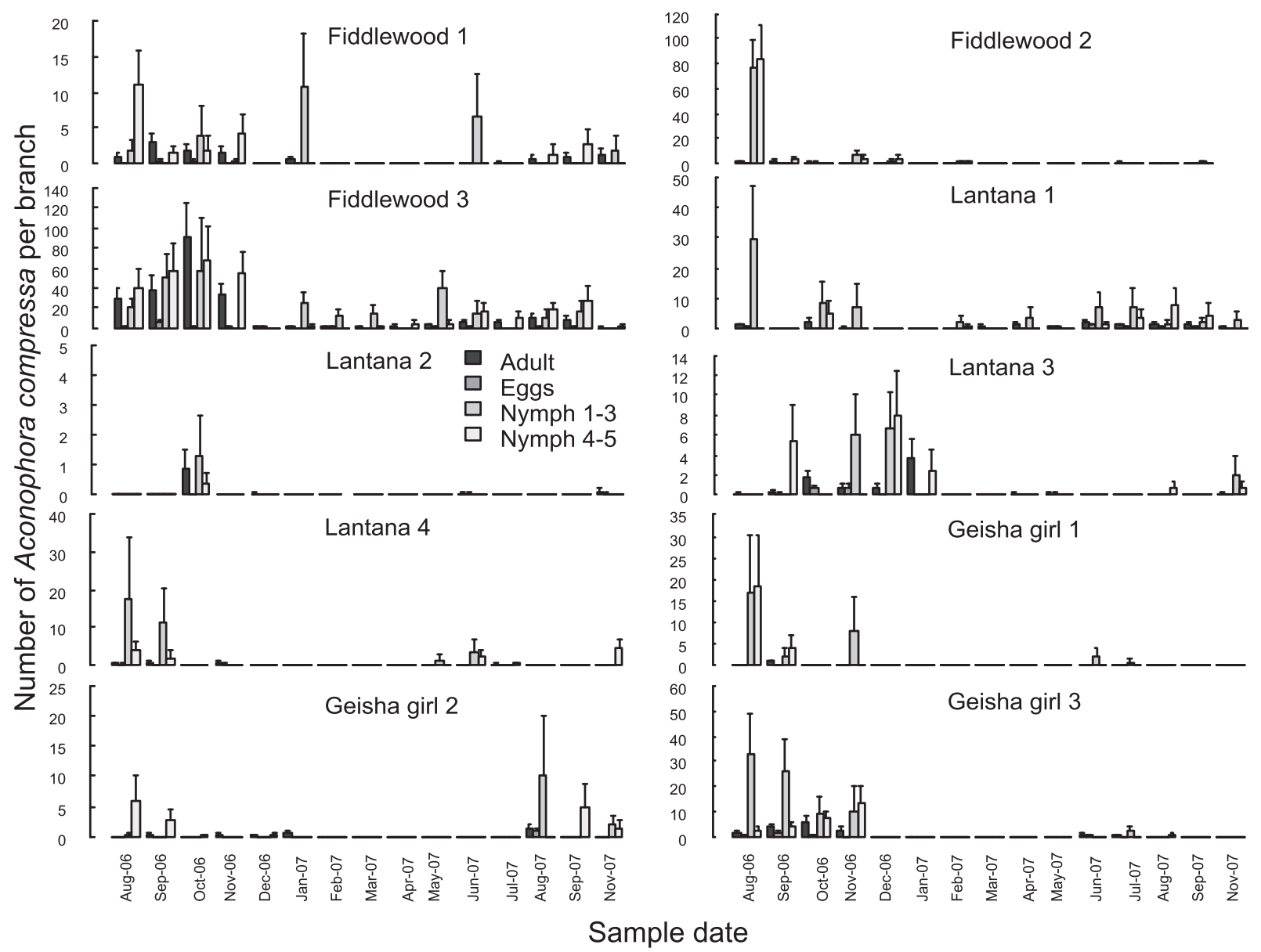

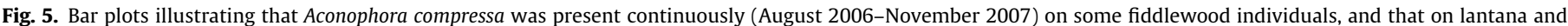

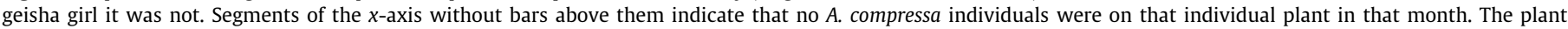
represented by Fiddlewood 2 (top right hand plot) was not sampled in August or September 2006. 
Table 3

Monthly climate data over the survey period. Means ( \pm S.E.) were calculated across sites for each month. No survey was conducted in October 2007.

\begin{tabular}{|c|c|c|c|c|}
\hline Month (survey month) & Maximum temperature $\left({ }^{\circ} \mathrm{C}\right)$ & Total number of days $\geqslant 30^{\circ} \mathrm{C}$ & Longest number of consecutive days $\geqslant 30^{\circ} \mathrm{C}$ & Rainfall (mm) \\
\hline August 2006 (1) & $28.3 \pm 0.85$ & $0.0 \pm 0.0$ & $0.0 \pm 0.0$ & $45.6 \pm 3.52$ \\
\hline September 2006 (2) & $28.3 \pm 0.75$ & $0.0 \pm 0.0$ & $0.0 \pm 0.0$ & $63.2 \pm 4.97$ \\
\hline October 2006 (3) & $32.9 \pm 1.30$ & $1.2 \pm 0.37$ & $0.8 \pm 0.2$ & $20.4 \pm 2.25$ \\
\hline November 2006 (4) & $34.0 \pm 0.98$ & $6.4 \pm 1.33$ & $3.4 \pm 0.6$ & $63.3 \pm 2.33$ \\
\hline December 2006 (5) & $31.4 \pm 0.75$ & $3.4 \pm 0.93$ & $1.4 \pm 0.40$ & $75.6 \pm 6.48$ \\
\hline January 2007 (6) & $34.0 \pm 0.76$ & $16.8 \pm 2.67$ & $10.0 \pm 1.76$ & $70.4 \pm 2.71$ \\
\hline February 2007 (7) & $30.8 \pm 0.75$ & $10.0 \pm 3.10$ & $5.2 \pm 2.60$ & $74.7 \pm 10.54$ \\
\hline March 2007 (8) & $35.6 \pm 1.04$ & $15.8 \pm 3.87$ & $6.4 \pm 1.44$ & $42.1 \pm 13.07$ \\
\hline April 2007 (9) & $28.7 \pm 0.60$ & $0.2 \pm 0.20$ & $0.2 \pm 0.20$ & $8.7 \pm 2.43$ \\
\hline May 2007 (10) & $29.8 \pm 0.75$ & $1.2 \pm 0.49$ & $1.2 \pm 0.49$ & $36.3 \pm 4.10$ \\
\hline June 2007 (11) & $25.3 \pm 0.85$ & $0.0 \pm 0.0$ & $0.0 \pm 0.0$ & $109.9 \pm 2.38$ \\
\hline July 2007 (12) & $25.6 \pm 0.78$ & $0.0 \pm 0.0$ & $0.0 \pm 0.0$ & $1.5 \pm 0.50$ \\
\hline August 2007 (13) & $27.4 \pm 0.86$ & $0.0 \pm 0.0$ & $0.0 \pm 0.0$ & $103.4 \pm 5.35$ \\
\hline September 2007 (14) & $30.8 \pm 0.97$ & $4.2 \pm 1.11$ & $2.2 \pm 0.58$ & $36.2 \pm 4.24$ \\
\hline October 2007 & $32.9 \pm 0.93$ & $7.2 \pm 2.27$ & $2.2 \pm 0.8$ & $90.9 \pm 9.00$ \\
\hline November 2007 (15) & $31.1 \pm 0.80$ & $1.8 \pm 0.58$ & $1.8 \pm 0.58$ & $80.1 \pm 3.12$ \\
\hline
\end{tabular}

other host species. Regularity and intensity of host use were lower on lantana, followed by geisha girl, Sheena's gold, jacaranda and myoporum.

Protracted periods of high summer temperatures $\left(\geqslant 30^{\circ} \mathrm{C}\right)$ were recorded between November 2006 and March 2007 (Table 3). Numbers of $A$. compressa dropped considerably during this time period across all host plants (Fig. 2). The numbers of $A$. compressa

\section{Table 4}

Summary of the number of plants sampled with and without Aconophora compressa in various Mexican states. Surveys were completed over three weeks in January and February 2007, the dry season.

\begin{tabular}{|c|c|c|c|}
\hline Host plant & State & $\begin{array}{l}\text { Total plants } \\
\text { sampled }\end{array}$ & $\begin{array}{l}\text { A. compressa } \\
\text { present (\%) }\end{array}$ \\
\hline \multicolumn{4}{|l|}{ Asteraceae } \\
\hline \multirow{3}{*}{ Senecio spp. (jarilla) ${ }^{\mathrm{a}}$} & Mexico & 8 & 0 \\
\hline & Morelos & 29 & 0 \\
\hline & Puebla & 25 & 4.0 \\
\hline \multirow[t]{2}{*}{ Baccharis sp. } & Puebla & 3 & 0 \\
\hline & Tlaxcala & 5 & 0 \\
\hline \multicolumn{4}{|l|}{ Bignoniaceae } \\
\hline \multirow[t]{4}{*}{ Jacaranda mimosifolia } & Guerrero & 6 & 0 \\
\hline & Mexico & 1 & 0 \\
\hline & Morelos & 33 & 3.0 \\
\hline & Puebla & 7 & 0 \\
\hline \multirow[t]{3}{*}{ Tecoma stans } & Mexico & 3 & 0 \\
\hline & Morelos & 53 & 18.9 \\
\hline & Puebla & 15 & 0 \\
\hline \multicolumn{4}{|l|}{ Sapindaceae } \\
\hline \multirow[t]{3}{*}{ Dodonaea viscosa } & Morelos & 37 & 0 \\
\hline & Guerrero & 1 & 0 \\
\hline & Mexico & 1 & 0 \\
\hline \multicolumn{4}{|l|}{ Hydrophyllaceae } \\
\hline \multirow[t]{3}{*}{ Wigandia spp. } & Mexico & 7 & 14.3 \\
\hline & Morelos & 31 & 0 \\
\hline & Puebla & 9 & 0 \\
\hline \multicolumn{4}{|l|}{ Verbenaceae } \\
\hline Aloysia triphylla (lemon verbena) & Morelos & 23 & 26.1 \\
\hline Citharexylum sp. (fiddlewood) & Mexico & 4 & 0 \\
\hline C. cinereum (fiddlewood) & Puebla & 11 & 9.1 \\
\hline D. erecta & Morelos & 24 & 62.5 \\
\hline \multirow[t]{3}{*}{ L. urticifolia (lantana) } & Mexico & 1 & 0 \\
\hline & Morelos & 65 & 30.8 \\
\hline & Puebla & 16 & 6.3 \\
\hline \multicolumn{4}{|l|}{ Unknown spp. } \\
\hline 4 taxa & Morelos & 56 & 0 \\
\hline 2 taxa & Puebla & 10 & 0 \\
\hline 2 taxa & Tlaxcala & 11 & 0 \\
\hline
\end{tabular}

\footnotetext{
a Jarilla, a common name in Mexico, probably represents more than one Senecio
} species with similar morphology and growth form. increased on fiddlewood, lantana and geisha girl from April 2007; numbers on Sheena's gold, jacaranda and myoporum remained very low (Fig. 2).

\subsection{Survey in Mexico}

Overall, about 450 plants were sampled from about 15 host taxa (Table 4). The abundance of $A$. compressa in Mexico was relatively low, on all host plants, compared to its abundance in Australia. A. compressa was more abundant in Morelos than any other area surveyed (Fig. 6; Table 4). In Morelos it was found at similar relatively high rates on $D$. erecta, L. urticifolia and T. stans (Fig. 6a). Abundance was very low on lemon verbena (Aloysia citriodora (Cav.) Ort.: Verbenaceae) and jacaranda (Fig. 6a). Citharexylum spp. were not found in Morelos despite extensive search.

In Puebla, A. compressa was found on three plants, one each of $C$. cinereum L., L. urticifolia and Senecio spp. (colloquial name 'jarilla', which possibly represents a number of plant species across the different regions surveyed) (Fig. 6b). A single male A. compressa was found on Wigandia spp. (Hydrophyllaceae) in the state of Mexico but was not found on this plant anywhere else despite sampling this species in areas in which A. compressa was in relatively high abundance (Table 4). Otherwise, $A$. compressa was not found outside Morelos and Puebla (Table 4).

\section{Discussion}

Early determination of multiple host use by herbivore species can be made and hosts can be categorised in an ecologically meaningful way from quantitative field surveys of multiple host plant species over time. The categorisations derived here correlate well with those derived from nymphal rearing experiments across the host plants sampled in Australia (Manners and Walter, 2009) and also from adult performance tests on these plants (Manners et al., 2010). The results presented here also demonstrate that the host plant associations of $A$. compressa are consistent across geographic regions sampled, in terms of which plant species are used as primary, secondary or incidental hosts (Figs. 2-5, Tables 1 and 2). Further sampling is needed in the native range, but the results have clear implications for biocontrol practice, as explained below.

\subsection{A. compressa in Australia}

The abundance of $A$. compressa on fiddlewood was always higher than on any other host sampled, in terms of the mean number of A. compressa per branch (Fig. 2) and proportion of trees with $A$. 


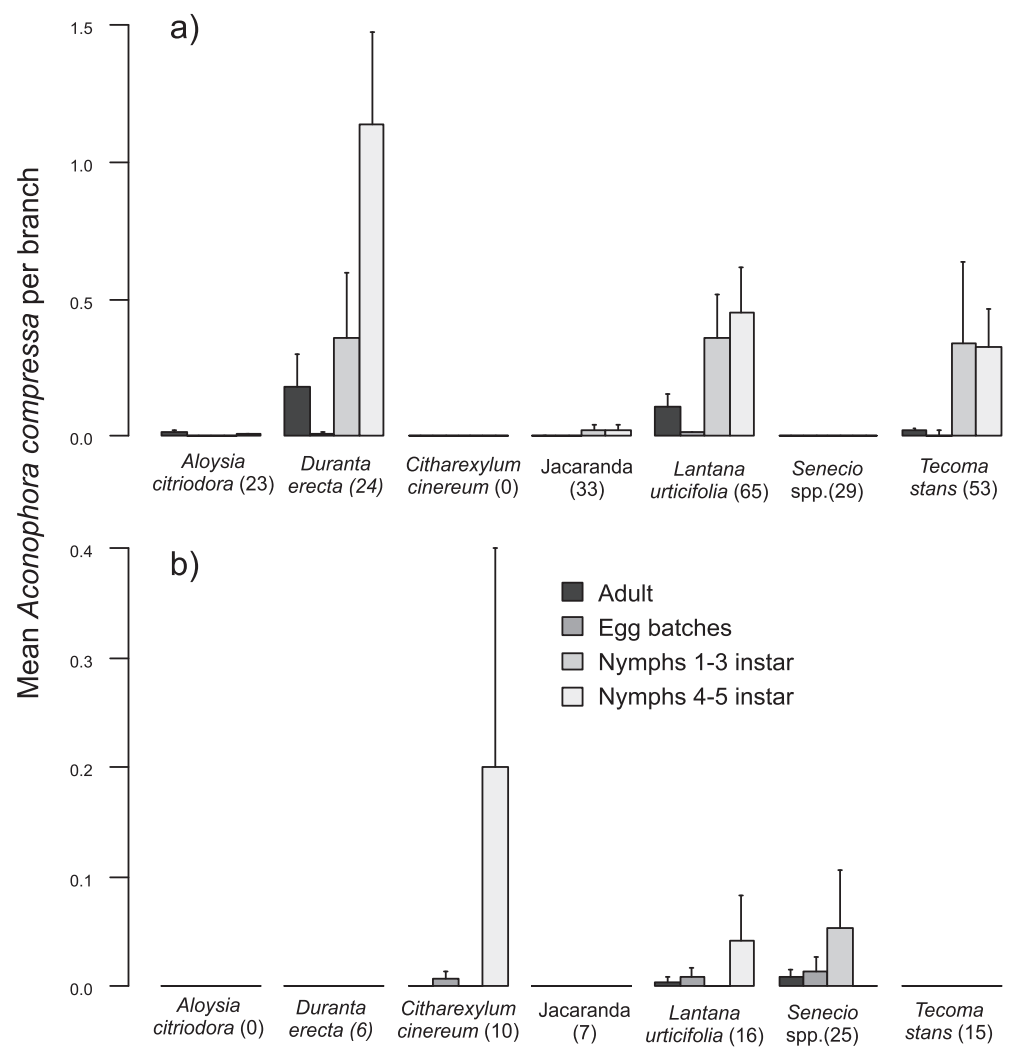

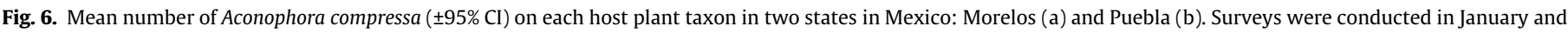
February 2007. Numbers in parentheses indicate the number of plants of each taxon sampled in each geographical area.

compressa (Fig. 3). The relative proportion of $A$. compressa adults and nymphs, compared to fiddlewood, on each host species was never more than $15 \%$ and $30 \%$, respectively, of that on fiddlewood in any given month (Fig. 4), but was usually much lower. Results indicate that lantana, geisha girl, Sheena's gold, myoporum and jacaranda were used mostly as a "spill-over" from fiddlewood (Figs 2-4). Only fiddlewood trees harboured $A$. compressa continuously (Table 2, Fig. 5) and recolonisation of secondary host plants occurred repeatedly over the course of the surveys (Figs. 2 and 5). Furthermore, the use of secondary and incidental host plants appears ephemeral, perhaps as a result of adults that developed from eggs laid on the secondary and incidental hosts emigrating soon after eclosion. However, this possibility would require a separate test.

In general, the results presented here provide further support that fiddlewood is the primary host plant of A. compressa in Australia and that all other hosts, including lantana, are secondary or incidental hosts (Manners and Walter, 2009; Manners et al., 2010). A. compressa has been recorded on particular lantana plants for periods of about 26 weeks (double that recorded in this study - Table 2) and at moderately high levels (about three to five times that recorded in this study) in 2009 and 2010, at the Alan Fletcher Research Station, Sherwood, Brisbane, Australia. Such populations on lantana have been recorded only as relatively isolated patches of these insects in New South Wales and Queensland (W.A. Palmer, unpublished data). The relative abundance of $A$. compressa on fiddlewood and other host species near these relatively large populations of $A$. compressa on lantana is not known.

The statistical analysis grouped Sheena's gold with jacaranda and myoporum, rather than with lantana and geisha girl, even though Sheena's gold is used more regularly and at somewhat higher abundance than jacaranda and myoporum (Figs. 2-4; Tables
2). Sheena's gold may thus be a relatively low ranking secondary host.

\subsection{A. compressa in Mexico}

The overall abundances of $A$. compressa on host plants in Mexico were much lower than those recorded in Australia (Fig. 6), but patterns of host use were similar across the two regions (Figs. 2-4). In the state of Morelos, A. compressa was found on a number of plant species, mainly from the family Verbenaceae, but also some from relatively distantly related families (Table 4 ). A. compressa was found on $D$. erecta and T. stans at levels similar to lantana (Table 4; Fig. 6). Counts of A. compressa on Lantana spp. in Mexico between 1989 and 1993 indicate that numbers are sometimes much higher (e.g. 40-100 adults per plant) than results presented here (W.A. Palmer, unpublished data). The results support the notion that host plant surveys in the native range should not focus exclusively on the target plant species (Walter, 2003; Sheppard et al., 2006a). The extent to which non-target plant species are surveyed remains problematic. It may be possible to formalise a native range 'search list' similar to those plants included for host testing. In any case, effort should be made to survey all possible plant species from the same family and of similar growth habit to the suspected primary host species in regions where the herbivore is relatively abundant.

Host plant use by $A$. compressa in Morelos also provides evidence that a number of the plant species used in Australia would have been anticipated if non-target plants had been surveyed prior to its release. These include $D$. erecta, jacaranda, $A$. citriodora and $T$. stans (quantitative surveys have not been conducted on the latter two species in Australia, although Palmer et al. (2004) documented the presence of $A$. compressa on these hosts). The original host testing indicated that $D$. erecta was suitable for development by $A$. 
compressa (Palmer et al. 1996) and had been found on D. erecta in Mexico prior to its release in Australia (Palmer and Pullen, 1995; Palmer et al., 1996).

This field survey of $A$. compressa in Morelos indicates that $L$. urticifolia, $D$. erecta and $T$. stans are in the same category of hosts (i.e. either primary or secondary) and jacaranda and A. citriodora are in a lesser category (i.e. either secondary or incidental hosts). More information is required to determine whether $L$. urticifolia, $D$. erecta and $T$. stans are primary or secondary hosts in Mexico. Essentially, data over multiple seasons on each host plant are required to understand this aspect of $A$. compressa ecology in Mexico.

The relationship between $A$. compressa and Citharexylum spp. in Mexico remains somewhat ambiguous, perhaps influenced by a number of factors. Many Citharexylum spp. are present in Mexico, but $C$. spinosum has not been recorded (Moldenke, 1942). C. spinosum is native to the Caribbean and Florida but $A$. compressa is not known from these regions (Dietrich and Deitz, 1991). Fiddlewood plants in Mexico were, however, rare or had low apparency during the survey. Since Citharexylum spp. are deciduous and January to February is dry in Mexico, these plants possibly harbour A. compressa at other times. Long term field surveys, perhaps including adjacent geographic regions in the range of $A$. compressa (e.g. Guatemala), would help clarify the status of the relationship between A. compressa and fiddlewood in its native range. This would also aid in the determination of whether lantana and fiddlewood are primary or secondary host plants in Mexico.

Lantana in Australia was thought to be most closely related to lantana from Mexico (Scott 2002), although recent evidence suggests that it may be more closely related to lantana from Venezuela and the Dominican Republic (R. Watts, CSIRO, Plant Industries, Canberra, personal communication). In general, the points made above indicate just how crucial are full field surveys across all seasons in the native range of a weed to make an informed release decision. That is, long-term field surveys are more likely to provide an accurate indication of the host relationships of the herbivore with its host plants than will sole reliance on laboratory or glasshouse based tests in quarantine. The latter, however, are important to interpret the field results and will provide the sole information on plants not present in the native range.

\section{Acknowledgments}

Thanks to Dhileepan and Dane Panetta who provided helpful comments on previous drafts of this paper and Simon Blomberg who provided statistical assistance that aided this paper significantly. This research was funded by a PhD scholarship from the CRC for Australian Weed Management. Overseas travel was funded by a University of Queensland travel grant and the CRC for Australian Weed Management.

\section{References}

Briese, D.T., 2005. Translating host-specificity test results into the real world: the need to harmonize the yin and yang of current testing procedures. Biological Control 35, 208-214.
Dhileepan, K. et al., 2005. Effect of temperature on the survival of Aconophora compressa Walker (Hemiptera: Membracidae): implications for weed biocontrol. Australian Journal of Entomology 44, 457-462.

Dhileepan, K. et al., 2006. Temporal patterns in incidence and abundance of Aconophora compressa (Hemiptera: Membracidae), a biological control agent for Lantana camara, on target and nontarget plants. Environmental Entomology 35, 1001-1012.

Dietrich, C.H., Deitz, L.L., 1991. Revision of the Neotropical Treehopper Tribe Aconophorini (Homoptera: Membracidae). North Carolina Agricultural Research Service, Raleigh, North Carolina.

Goolsby, J.A. et al., 2006. Maximising the contribution of native-range studies towards the identification and prioritisation of weed biocontrol agents. Australian Journal of Entomology 45, 276-286.

Louda, S.M. et al., 2003. Nontarget effects-the achille's heel of biological control? Retrospective analysis to reduce risk associated with biocontrol introductions. Annual Review of Entomology 48, 365-396.

Manners, A.G. et al., 2010. Characterising insect plant host relationships facilitates understanding multiple host use. Arthropod-Plant Interactions 4, 7-17.

Manners, A.G., Walter, G.H., 2009. Multiple host use by a sap-sucking membracid: population consequences of nymphal development on primary and secondary host plant species. Arthropod Plant Interactions 3, 87-98.

Marohasy, J., 1996. Host shifts in biological weed control: real problems, semantic difficulties or poor science? International Journal of Pest Management 42, 7175.

Milne, M., Walter, G.H., 2000. Feeding and breeding across host plants within a locality by the widespread thrips Frankliniella schultzei, and the invasive potential of polyphagous herbivores. Diversity and Distributions 6, 243-257.

Moldenke, H., 1942. The Known Geographic Distribution of the Members of the Verbenaceae and Avicenniaceae. Edwards Brothers, Inc., New York.

Palmer, W.A. et al., 2004. Analysis of the non-target attack by the lantana sapsucking bug, Aconophora compressa, and its implications for biological control in Australia. In: Sindel, B.M., Johnson, S.B. (Eds.), 14th Australian Weeds Conference Vol. Weed Society of New South Wales Inc.. Sydney, Charles Sturt University, Wagga Wagga, NSW, pp. 341-344.

Palmer, W.A., Pullen, K.R., 1995. The phytophagous arthropods associated with Lantana camara, L. Hirsuta, L. urticifolia, and L. urticoides (Verbenaceae) in North America. Biological Control 5, 54-72.

Palmer, W.A. et al., 1996. The host range of Aconophora compressa Walker (Homoptera: Membracidae): a potential biological control agent for Lantana camara L. (Verbenaceae). Proceedings of the Entomological Society of Washington 98, 617-624.

Rajapakse, C.N.K. et al., 2006. Host recognition by a polyphagous lepidopteran (Helicoverpa armigera): primary host plants, host produced volatiles and neurosensory stimulation. Physiological Entomology 31, 270-277.

Sheppard, A. et al., 2006a. Native-range research assists risk analysis for non-targets in weed biological control: the cautionary tale of the broom seed beetle. Australian Journal of Entomology 45, 292-297.

Sheppard, A. W., et al., 2006b. Biological control of brooms in Australia: an update. 15th Australian Weeds Conference, Papers and Proceedings, Adelaide, South Australia, 24-28 September 2006: Managing weeds in a changing climate. 573576.

Simberloff, D., Stiling, P., 1996. How risky is biological control? Ecology 77, 19651974.

Walter, G.H., 2003. Insect Pest Management and Ecological Research. Cambridge University press, UK.

Walter, G.H., Benfield, M.D., 1994. Temporal host plant use in three polyphagous Heliothinae, with special reference to Helicoverpa punctigera (Wallengren) (Noctuidae: Lepidoptera). Australian Journal of Ecology 19, 458-465.

Wapshere, A.J., 1974. A strategy for evaluating the safety of organisms for biological weed control. Annals of Applied Biology 77, 201-211.

Wapshere, A.J. et al., 1989. Recent developments in biological control of weeds. Crop Protection 8, 227-250.

Withers, T.M., Barton Browne, L., 1998. Possible causes of apparently indiscriminate oviposition in host specificity tests using phytophagous insects. In: Zalucki, M.P., Drew, R.A.I., White, G. (Eds.), Proceedings of the 6th Australiasian Applied Entomological Research Conference. Brisbane, Australia, pp. 565-572. 